\section{Nuclear India}

\section{New reactor "not for bombs"}

New Delhi

INDIA has denied reports that the country's largest research reactor, commissioned on 8 August, is intended to breed plutonium for bombs to counter Pakistan's nuclear threat. A spokesman for the Department of Atomic Energy (DAE) says that the $100-\mathrm{MW}$ DHRUVA reactor at Bombay is capable of producing annually $30 \mathrm{~kg}$ of plutonium which will be outside international safeguards, "but it is not a dedicated facility". He says that like all uranium-fuelled reactors in the world, DHRUVA will breed plutonium, but is not linked with any weapons programme.

India is not in fact dependent solely on DHRUVA for plutonium if it did decide to go nuclear. It has been reprocessing spent fuel from CIRUS, an ageing Canadian-built 40-MW reactor operating in Bombay, since 1963. CIRUS was the source of plutonium for the nuclear test in Pokran in 1974 . Another $100 \mathrm{~kg}$ of plutonium, also from CIRUS, was used to make the Pu-U carbide fuel for the Fast Breeder Test Reactor (FBTR) which is nearing completion at Kalpakkam near Madras.

Neither CIRUS nor the first 230-MW unit of the Madras Atomic Power Plant (MAPP-I) which has been operating since 1983 is under safeguards; these apply to the US-built power plant in Tarapur, and the two atomic power reactors in Kota, Rajasthan. While Tarapur fuel has not yet been reprocessed, every gram of plutonium produced at Kota has been accounted for. India's current stock of plutonium is estimated to be at least 200 $\mathrm{kg}$. DAE officials point out that it is not from lack of plutonium but by a political decision that India has not been making bombs.

Four days after DHRUVA became critical, DAE commissioned MAPP-II, the second power plant in Madras. This "90 per cent indigenous" power plant, together with DHRUVA, which will replace CIRUS in five years, will no doubt add to the stockpile of unsafeguarded plutonium which DAE says is required to fuel the fast breeder reactors India plans to build in the 1990s. The FBTR, similar to France's RHAPSODIE, is expected to become critical in September and India is well advanced in the design of a 500-MW prototype commercial breeder.

According to DAE, the DHRUVA reactor will be used to produce isotopes for agriculture and medicine, besides research on solid state which requires a higher flux of neutrons than is available at CIRUS or APSARA - a one MW swimming pool reactor built in 1956 using British supplied enriched uranium. DHRUVA, which uses natural uranium fuel and a heavy water moderator, is designed for a flux of $10^{14}$ neutrons at the centre of the

Soviet alcoholism involving Jewish refusniks. drink. sequences. core, and is thus comparable to the NRX reactor of Canada. DHRUVA will, however, operate at full power only after DAE has solved the serious problem of vibration of fuel rods and ensured complete safety of the interlock systems. When one of the interlocks failed two days before the reactor went critical, four tonThe DHRUVA (left) and CIRUS (right) nuclear reactors.

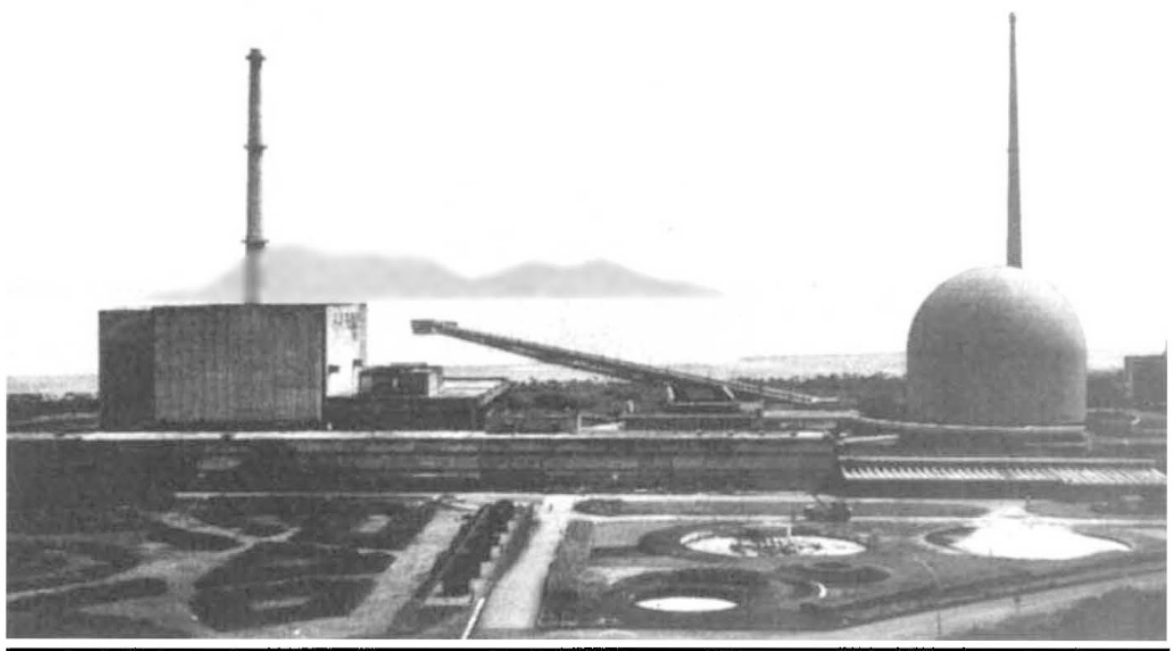

\section{Drunk driver stripped of degree}

THE Soviet Union's new campaign against alcohol abuse has cost at least one scientist his degree, and the lifelong financial benefits that go with it. The legal provisions, introduced in 1976, allowing those found guilty of conduct unbecoming to a Soviet citizen to be deprived of their degrees, has so far been used only in a handful of cases

The penalty has now been imposed in the bizarre case of Boris Samarin, a former employee of Leningrad University, who is just completing a four-year sentence for causing the deaths of six companions while driving under the influence of

The accident, which took place in the small Karelian village of Suoyarvi, involved members of the Leningrad University Karelian Geophysical Expedition, headed by Samarin. On the way back from the expedition, Samarin was travelling in the cabin of the expedition truck, and both he and the driver, Viktor Kolesnik, were drinking heavily. When the truck ran off the road into a swamp, all six people in the body of the truck, three girl students, two women scientists and the small son of one of the latter, were drowned, Samarin and Kolesnik escaped to face the legal con-

Court cases are normally reported in the Soviet press only to illustrate some facet of current policy, and it was only last August, more than three years after the nes of heavy water worth $£ 0.75$ million were spilt. MAPP-II, which went critical without a hitch, is expected to be synchronized with the power grid in November. With the commissioning of the country's sixth nuclear power reactor, the nuclear contribution to India's total power capacity will reach $1,320 \mathrm{MW}$, or four per cent. The target, according to Dr Raja Ramanna, chairman of the Atomic Energy Commission, is $10,000 \mathrm{MW}$ by the year 2000 .

K.S. Jayaraman

crash, that the Moscow Literaturnaya Gazeta carried an extensive article on the incident, pointing out that Samarin was well known to be a heavy drinker, that members of the hydrogeology department were reluctant to go on expeditions with him (indeed, his expeditions regularly included a number of "dead souls", who figured in the official report but who had never actually left Leningrad), and that, nevertheless, no apparent efforts were made to curb his drunkenness nor to take the organization and running of expeditions out of his hands. How, asked the Literaturnaya Gazeta, could such a situation arise? printed a reply from the rector and the secretary of the Party Committee of Leningrad University. This, in effect, pointed out that the unfortunate incident had taken place three years previously, and that as a result of the tragedy, procedures relating to university personnel and to the organization of expeditions had been considerably revised.

Last month, as a postscript to the whole affair, the paper noted that it had received a letter from Dr G.M. Nesmeyanov, the head of the Higher Attestation Committee, VAK, the body responsible for higher degrees, saying that Samarin had now been deprived of the degree of Candidate of Geological and Mineralogical Sciences.

Vera Rich
A few weeks later, the newspaper 